\title{
Applying Soundness Standards to Qualified Reasoning ${ }^{1}$
}

\section{ROBERT H. ENNIS}

\author{
University of Illinois \\ Urbana-Champaign
}

\begin{abstract}
Defining 'qualified reasoning' as reasoning containing such loose qualifying words as 'probably,' 'usually,' 'probable,' 'likely,' 'ceteris paribus,' and 'prima facie,' Ennis argues that typical cases of qualified reasoning, though they might be good arguments, are deductively invalid, implying that such arguments fail soundness standards. He considers and rejects several possible alternative ways of viewing such cases, ending with a proposal for applying qualified soundness standards, which requires employment of sufficient background knowledge, sensitivity, experience and understanding of the situation. All of this takes place as part of the process, introduced elsewhere, of successively applying different legitimate sets of standards until one is found that is satisfied, or none is found, the latter calling for rejection of the argument, the former calling for its acceptance.
\end{abstract}

Résumé: Un raisonnement nuancé contient des mots tels que "probablement," "généralement," "probable," "vraisemblable", "ceteris paribus", et "prima facie". Ennis avance que ces raisonnements sont typiquement déductivement non valide, bien qu'ils puissent appuyer fortement leur conclusion. L'auteur prend en considération et ensuite rejette différentes tentatives d'évaluer ces raisonnements. Il propose que leur évaluation requière un usage judicieux et flexible des connaissances d'arrière-plan suffisantes et d'une compréhension de la situation. Tout ceci a lieu dans un procédé dans lequel on applique successivement différents ensembles de normes jusqu'à ce que l'on en trouve un qui légitime un raisonnement en question. Si on réussit à en trouver, le raisonnement est acceptable, si on ne réussit pas, il est inacceptable.

Keywords: Deductive validity, soundness, qualified reasoning, nonmonotonic reasoning, probable, probably, argument appraisal strategy, subjective probability, validity, ceteris paribus, prima facie, argument, argument standards, conduction, situation, background knowledge, critical thinking, informal logic.

\section{Introduction}

Much reasoning in our everyday lives implicitly or explicitly includes imprecise qualifying words like 'usually,' 'rarely,' 'probably,' 'probable,' 'likely,' 'almost certainly,' 'ceteris paribus,' and 'prima facie,' although the last two of these are not in the vocabularies of most people and must usually be inferred from what they do or say. I shall call such reasoning 'qualified reasoning.' In this essay, the focus is on qualified reasoning, arguments 1 ) that are being judged for their ability to justify their conclusions; and, 2) to which soundness standards are being ap- 
plied, including acceptability-or truth-of reasons. Either a truth approach or an acceptability approach can be accommodated by the position taken in this essay.

Soundness standards, in the language of many textbooks in deductive logic, require both deductive validity of the reasoning and acceptability-or truth-of the reason(s). I often hesitate to use the term 'sound' in this way because of my fear of confusing the large number of people for whom a sound argument need not be deductively valid, but I shall repress this hesitation in this essay because in this context, using the word 'sound' in its technical sense is an efficient way to communicate.

This essay is the development of one aspect of a larger effort outlined in my "Argument Appraisal Strategy: A Comprehensive Approach" (2001). In this larger effort, I argued that the distinction between deductive and inductive arguments is not viable in most contexts, and in particular is not helpful as a way to decide whether to apply deductive or inductive standards in the appraisal of an argument; although the distinction between inductive and deductive standards is a viable distinction. ${ }^{2}$ Accordingly, I rejected a commonly-recommended approach to appraising arguments: Classify the argument, and then apply the standards dictated by the classification. I suggested instead that a better approach to argument appraisal, rather than requiring classification prior to appraisal, involves the successive application of different legitimate sets of standards, such as soundness standards, the decision strategy being to reject an argument that satisfies no legitimate set of standards, and accept one that satisfies some legitimate set of standards, the latter choice implying the acceptance of the argument's conclusion. I avoided urging a specific taxonomy of argument standards on the assumption that the successiveapplication-of-standards approach would work well for any reasonably comprehensive taxonomy of argument standards.

The limited goals in the current essay are 1) to argue that typical cases of qualified reasoning are not sound, even if they would be sound if the qualifiers were removed; 2) to show that various related arguments are not sound or have other defects; 3 ) to consider and evaluate one existing proposed way to deal to deal with unsound arguments, Trudy Govier's (1999) conductive reasoning approach; and, 4) to suggest and elaborate another way to deal with such arguments, a way I use myself, one that involves some loosening of soundness standards. Thus, this essay is concerned with one part of the overall successive-applicationof-standards approach: the application and loosening of soundness standards in cases of qualified reasoning.

The limited goals of this essay can be pursued without our becoming involved in the controversy about the exact nature of deductive logic (although I do have a position, which is basically unchanged since Ennis, 1981) because, even though there is some disagreement about exactly what a complete set of deductive standards should be, there is sufficient agreement on them to handle real cases of reasoning that people, including Supreme Court Justices and automobile mechan- 
ics, do in their everyday lives-if we ignore the implying of the paradoxes of material implication and their cohorts.

A first move in the pursuit of these limited goals is to show typical cases of qualified reasoning that are not deductively valid (though they would be deductively valid if the qualifiers were removed), and that therefore would not, as is, satisfy strict soundness standards, even though they are good arguments. I shall consider several typical examples, the first being one that I once offered to a guest. I believe it to be a good argument, justifying its conclusion, "The raccoon will probably not bother you." 3

\section{The Raccoon Argument:}

Raccoons rarely attack a human when they do not feel threatened and do not feel that their young are threatened. The raccoon that is ambling across the yard does not feel threatened by us, and it does not feel that its young are threatened-its young are not around. So the raccoon will probably not bother you, even though you are within fifteen feet of it.

The occurrence of the qualifiers, 'rarely' and 'probably' in this argument make this a case of qualified reasoning.

I shall argue that this argument does not satisfy strict soundness standards because it is not deductively valid. I believe that it also does not satisfy any other commonly-accepted, legitimate set of standards. It thus appears to present an apparent dilemma for me: a good argument that seemingly by my broad approach must be rejected because it does not satisfy any commonly-accepted legitimate set of standards.

The apparent dilemma, I suggest, can be resolved by loosening soundness standards in the way later to be described-to accommodate qualified reasoning. This loosening, incidentally, would make deductive validity more widely applicable than many of its detractors believe because many real arguments that approach deductive validity are cases of qualified reasoning.

In the first two parts of this essay, I shall contend 1) that the raccoon argument is not deductively valid; 2) that instructive variations of arguments using qualifiers are not deductively valid or are otherwise defective, though some people might think otherwise; and 3) that attempts to substitute probability numbers for qualifiers as well as to resort to subjective probability approaches are not helpful.

Michael Scriven (2003, p. 24) has noted the problem that formal logic has in appraising qualified reasoning. But at that time he offered no concrete way to deal with it, nor did he actually argue that arguments like the raccoon argument are not deductively valid. 


\section{Deductively Invalid-or Unhelpful-Arguments}

There is an initial plausibility to a judgment that the raccoon argument is deductively valid. After all, there is a qualification in the reasons and an accommodating one in the conclusion of an argument that is otherwise apparently deductivelyvalid-if we allow for loose idiomatic transformations. Stephen Toulmin, Perry Weddle, and Alvin Plantinga, among others, are willing to ascribe deductive validity to related examples, though Plantinga hedges with a limited-to-the-evidence qualification. Here are examples from their work:

Toulmin: "Petersen is a Swede; scarcely any Swedes are Roman Catholics; so, almost certainly, Peterson is not a Roman Catholic" (1964, p. 131).

Weddle: "When a low pressure ridge moves down from the Gulf of Alaska (etc.), we usually [in Sacramento, California] get rain the next day, and a low pressure ridge is moving down right now (etc.); hence, it is likely to rain tomorrow" (1979, p. 3).

Plantinga: "Feike can swim is probable with respect to 99 of $100 \mathrm{Fri}$ sian lifeguards can swim and Feike is a Frisian lifeguard" (1993, p. 161 , italics in original).

Each of these arguments, which their authors claim to be deductively valid, is instructive in its own way. But before considering them, I will show why I think the raccoon argument is not deductively valid.

I might well believe the first two propositions of the raccoon argument, but also observe that the raccoon is foaming at the mouth, and consequently believe that the raccoon might be rabid. In that case, it would be wise not to assert the conclusion that the raccoon probably will not bother you. It might well be wrong to say that the raccoon probably will not bother you. How then could the conclusion follow necessarily from the reasons? The denial of the conclusion would not contradict the assertion of the premises. This confluence of possible circumstances constitutes a counterexample to a claim of deductive validity for the raccoon argument.

Toulmin's Petersen. Toulmin claims that the Petersen argument is 'valid' and 'analytic' (Toulmin, pp. 131-34). However, suppose that we visit a unique, almostexclusively Roman Catholic town in Sweden, meet Petersen in a shop, strike up a conversation with him, and learn that he has lived there all his life. At that point, given that we know nothing more that is relevant to the determination of his religion, we have no right to claim that he is almost certainly not a Roman Catholic, even though we know that scarcely any Swedes are Roman Catholics and that Petersen is a Swede. On further thorough investigation, we might well be justified in saying that Peterson probably is a Roman Catholic, which would require denying that he is almost certainly not a Roman Catholic, even if Toulmin's two premises are acceptable-or true. Suppose that this further thorough investigation has occurred, 
justifying the denial of Toulmin's conclusion. If the denial of the conclusion contradicts the assertion of the premises (or, in the language of truth, if the conclusion might be false when the two premises are true), the argument is not deductively valid. Toulmin's Petersen argument is not deductively valid and is quite similar to my raccoon argument.

Paradoxically, Toulmin admits that we could "know something further about Petersen which places him very probably in the Roman Catholic minority" (p. 133). But if he entertains that possibility, then he should realize that, even given the truth of his premises, the conclusion that Petersen is almost certainly a Swede could be false. That is, if this "something further" obtains, then it is not the case that "almost certainly Petersen is not a Roman Catholic." But if the argument is deductively valid, and if the premises are true, then this result is logically impossible.

Weddle's 'usually,' 'likely, ' and 'etc. ' Perry Weddle's use of 'usually' in his generalization and 'likely' in his conclusion make his argument at first glance also much like the raccoon argument. The 'usually' tells us that there are times when a low pressure area's moving down from the Gulf of Alaska is not followed by rain in Sacramento. Suppose that in a particular case we have good reason to believe that this is one of these times. For example, suppose that there is a cold front moving unexpectedly rapidly to the northeast, effectively blocking the low. Then it would not be likely that there would be rain in Sacramento tomorrow. So the conclusion could be false even though the premises be true, making the argument invalid, assuming that the occurrence of 'etc.' in the second reason does not include the ruling out of this unexpected sudden movement of the cold front.

If that 'etc.' does include the ruling out of the unexpected sudden movement of the cold front, then I could substitute some other factor that could interfere, a factor that is not covered by the 'etc.' I am here assuming that the coverage of the 'etc.' is not all the logically-possible interfering factors, that is, that its coverage is not infinite. This assumption is justified because if the coverage of 'etc.' were infinite, then the argument would be useless because it would be impossible to establish the second premise, since it would then be about an infinite number of things.

'Ceteris Paribus' and 'Etc. ' Suppose that the words 'usually' and 'etc.' were not in the argument but that the phrase, 'ceteris paribus' were added to the first premise. I make this supposition so that I can use this context in order to discuss the typical role of the important qualifier, 'ceteris paribus.' Although Weddle did not use the phrase, 'ceteris paribus,' he could have used it to make an argument. Then the wording of the argument would become:

When a low pressure ridge moves down from the Gulf of Alaska, ceteris paribus, we [in Sacramento, California] get rain the next day, and a low pressure ridge is moving down right now; hence, it is likely to rain tomorrow. 
Literally, as I understand it, 'ceteris paribus ' means 'other things being equal' (or remaining the same), leaving it vague what these other things are that are supposed to be equal (or remain the same). Regardless, the second premise ("a low pressure ridge is moving down right now") does not claim that other things are equal, so the argument is not deductively valid. The above-mentioned cold front could interfere with the rain, so it would be possible for the premises to be true and the conclusion false, showing the revised argument to be deductively invalid.

In the unlikely event that the second premise were amended to include a claim that ceteris paribus holds (that is, that other things are the same), we would still have a problem of some sort. Assuming that the phrase, 'ceteris paribus', is finite and vague (that is, not fully predesignating), then there is no stated assurance that the coverage of the two occurrences of 'ceteris paribus' cover the same things. In that case the second premise might not protect against an occurrence that comes under the 'ceteris paribus' of the first premise. Then premises might both be true while the conclusion false, and the argument would be deductively invalid.

If instead we have the assurance that the two occurrences of ceteris paribus cover the same things, and we still do not know what these things are, it would not be possible to establish soundness. If, on the other hand, we do know the exact coverage of this phrase on both occurrences and both are the same, then the argument could be deductively valid, but it would not be a case of qualified reasoning. The phrase 'ceteris paribus' would be an abbreviation, not a qualifier.

Alternatively, assume that the coverage of 'ceteris paribus' is infinite. In that case there would be no way to establish the second premise; so the argument could never be shown to have true premises; so the argument could never be shown to be sound; so the conclusion could not be established.

In sum, 'ceteris paribus' as ordinarily used destroys the establishment of soundness.

A similar analysis shows that the use of the term 'etc.' (even without the 'usually' and 'likely' that are in Weddle's argument), when 'etc.' is used (as it usually is) as a deliberately vague term, destroys the establishment of soundness. But I will not here take the time and space to show this.

'Ceteris paribus' and 'etc.' have similar characteristics. Each of them makes the argument deductively invalid if it appears only in the first premise. If it appears also in the second premise, and the coverage is finite, then again the argument is deductively invalid or the argument is not qualified or is not assessable; or if the coverage is infinite, we cannot determine whether the second premise is established, making it impossible to tell whether the argument is sound. If we are unable to tell whether an argument is sound, we have no right to assert its conclusion on the basis of the argument. 
Please be aware that I am not condemning the use of the terms, 'ceteris paribus' and 'etc.' or the ideas they express. On the contrary, I feel that these qualifiers are very useful. But they preclude showing unqualified soundness.

'On the Evidence Provided' and Similar Protective Qualifications. It is not clear to me that Plantinga's qualification, 'with respect to,' succeeds in shielding the alleged deductive validity of his argument against the sort of counterexamples that I have offered in the previous cases, even though a counterexample would introduce more facts about the situation, which the qualification is apparently supposed to preclude. Other phrases he uses to achieve the same effect are "on the evidence provided" (p. 162) and "given just that evidence" (p. 161), similarly signaling the ignoring of any other factors, known or unknown, that might be relevant.

Suppose that Feike's mother is Chief Administrator of the Frisian Islands, and that her administration is corrupt, rife with nepotism and influence peddling. Furthermore, suppose that Feike has always been placed as a redundant lifeguard in the beach positions to which he has been assigned. Even if "with respect to" would seem to force us to ignore these supposed facts in drawing as a conclusion that it is probable that Feike can swim, they can not be ignored when one uses the phrase, 'it is probable,' because that phrase implies that it is reasonable to believe the proposition. However, it is not reasonable to believe a proposition when that belief is based on a closing of one's mind to further evidence. Putting it in another way, on the basis of just the two pieces of evidence provided by Plantinga, it is not the case that the conclusion is probable. No conclusion about Feike's swimming prowess is probable; the appropriate thing to do is to withhold judgment. More evidence is needed. One should not be willing to draw such a conclusion without considering whether the sample on which the 99-out-of-100 generalization was based is unbiased, if the generalization was based on a sample; one should wonder whether there is reason to think Feike is a typical Frisian lifeguard; and one should wonder whether any person that has an influence on the decision that 99 out of 100 is the correct ratio and on the selection of Feike, is competent and unbiased. If no other evidence than the two basic facts is allowed, then no judgment should be allowed either.

I am not saying that if the two pieces of evidence in the original argument were absolutely all I had, I would not in a forced-choice situation choose the proposition that Feike can swim over the proposition that Feike can not swim. But that does not make the proposition reasonable to believe.

If, on the other hand, I am wrong in seeing the implication by 'probable' of reasonable belief, then the trouble with these limited-to-the-evidence qualifications is that the conclusion would not then be the sort of thing we want to know in most real situations because all we learn under such a qualification is what the evidence to which reference is made suggests on its own, no matter how incomplete or one-sided that evidence may be. To elaborate: 


\section{Robert H. Ennis}

Suppose further that you are the new Chief Lifeguard at a Frisian beach, and are trying to decide to what position to assign Feike. One question of interest to you could well be, 'Is it probable that Feike can swim?' rather than "Is it probable that Feike can swim on just the evidence that 99 out of 100 Frisean lifeguards can swim and Feike is a Frisean lifeguard?" Under the political conditions I supposed above, offering Plantinga's argument is not responsive to your interest-or to most conceivable real interests. Adding the limited-to-the-evidence qualification actually could divert your attention from the matter of interest in this case as I have developed it. The frequency ratio, 99 to $1-$ with no other background evidence sought or considered-is by itself insufficient evidence for your concern.

I realize that sometimes an argument qualified with 'on the evidence provided' is good enough for the situation-when for example, we know (as additional evidence) that the arguer is an expert, has the habit of doing a thorough job of looking for evidence on both sides of a question, makes reference to all of the evidence discovered, and has no conflict of interest in this case. If the expert used the phrase 'on the evidence provided', we might well have confidence that the expert used much more evidence than that which is provided, and actually made a thorough investigation. But a simple frequency ratio like 99 to 1 all by itself -with no attempt to secure as much evidence as is feasible in the situation is not enough for making a useful decision-unless a yes-or-no decision is forced on us-in which case, I admit, we should do the best we can with what we have.

Statistical Syllogisms. To save time and space, I would like to use the Feike case to make my by-now standard point about another kind of argument, the statistical syllogism. For example, the deductive validity of the following argument:

99 of 100 Frisean lifeguards can swim, and

Feike is a Frisean lifeguard.

So, it is probable that Feike can swim (or Feike can swim).

would be vulnerable to the possible counter-evidence given above about the Frisian political situation. It is logically possible for the first two premises to be trueor acceptable-while the conclusion is false. So, this standard statistical syllogism is not deductively valid.

Deductively-Valid Qualified Reasoning. I do not want to give the impression that I am claiming that all qualified reasoning is deductively invalid. For example, I am not here challenging reasoning fitting the propositional schema, 'If $P$, then probably Q; P; so probably Q' and variants thereof, which contain the same qualifier as part of the same proposition throughout.

Nor do I want to challenge the deductive validity of arguments fitting the schema, 'Probably all A's are B's, $x$ is an A; so $x$ is probably a B,' and variants thereof. I see nothing deductively invalid about arguments that fit these two forms, but $I$ am open to instruction otherwise. 


\section{Assigning Numbers to the Qualifiers and Producing a Number for the Conclusion}

Objective Assignment. One approach to dealing with arguments containing one or more qualifiers explicitly or implicitly is to convert the terms into numbers varying from +1 to -1 , and then (often) do mathematics. For example, we could substitute 'with a probability (or plausibility, or strength-of-support) of .04' for the word "rarely" in the raccoon example. David Hitchcock, ${ }^{4}$ among others, including Nicholas Rescher in Plausible Reasoning (1976) and John Pollock in Cognitive Carpentry (1995), has suggested this idea. The result in Rescher's and Pollock's systems could be respectively a plausibility or strength-of-support syllogism with all qualifiers replaced by numbers and numbers assigned in every statement. Then calculations are performed using the numbers, and decisions are made.

A significant problem with these approaches is that there is no reasonable way to assign numbers to qualifiers and to transform numbers back into qualifiers. Numbers are precise and qualifiers are vague, making it unclear which location in the number spectrum to select. Consider: What number can we assign to 'rarely'? Why, for example, pick .04 for 'rarely' in the raccoon argument rather than .03 , or .0516 , or .067452939 ? In response, one might pick a range, say .03 to .05 ; but then we could ask why pick that range rather than .0101 to .06981 ? In response, one might suggest a .05 confidence interval of .0200 to .0516 , but why that confidence interval? Alternatively, one might assign a normal probability distribution with a mean of .04 and a standard deviation of .01 . But again why that particular range rather than, say, one with a mean of .04001 and a standard deviation of .009998 , or one with a mean of .06 and a standard deviation of .01 , and why a normal distribution instead of some other possibility?

I am reminded of Aristotle's advice to let the degree of precision fit the subject matter. ${ }^{5}$ The qualifier, 'rarely,' is too vague and lacking in sufficient focus to assign a number, or range, or confidence interval, or probability distribution to it without being arbitrary about it. When I, the arguer, made the statement about raccoons, I had no number in mind, and could not have produced one if asked. Yet the qualified generalization is true.

It is even stranger to assign numbers to 'ceteris paribus' and 'prima facie.' That boggles the mind.

The systems actually worked out by Rescher and Pollock have many complexities that I have not presented. But the complexities do not eliminate this basic difficulty. A second problem, though I can not argue it here, is the neglect of a commitment or limited guarantee that seems to occur when 'probably,' 'probable,' 'likely,' etc. are converted to numbers in a conclusion. Toulmin $(1956,1964)$ and Urmson (1956) have urged the commitment/limited-guarantee position I tentatively hold, but to my knowledge the issue has not been adequately explored. To deal fairly with this issue here would take too much space and time to do it justice. 
However, my argument in this essay is not crucially dependent on the position urged by Toulmin and Urmson on the issue, a position I am currently further exploring.

Subjective Probabilities. Another currently-popular way to assign numbers is to treat statements containing qualifiers (as well as straight probability statements that contain numbers) as statements of strength of belief, expressible in numbers (ranging from +1 to -1 ). Under that approach, the conclusion of the basic raccoon argument could become:

My strength of belief that the raccoon will not bother you is 96 .

As before, a range or a confidence interval, or a probability-like strength-ofbelief distribution could also be used (although it is difficult to imagine that most people could understand and report these more complex beliefs). My previous comment to the effect that 'rarely' and other qualifiers are vague could then be countered by saying that we each could give our own numerical meaning to them, and accordingly that each time we use them, the expression of strength of belief is within the control of each believer according to the varying ranges, strengths, distributions, and degrees of precision felt desirable by the believer.

Unfortunately, there are strong objections to this subjective approach. I shall give two that show that such substitutions radically affect what we are saying when we use qualifiers.

First, the subjective approach wipes out real disagreements among people. If A says, "Probably the raccoon will not bother you," and B says, "Probably the raccoon will bother you," they are disagreeing with each other. But under the subjective probability interpretation, they are not disagreeing with each other. A would be saying that A's strength of belief that the raccoon will not bother you is, say, .96, something to which B can readily agree. That is, B can readily agree that A's strength of belief is .96 . The disagreement disappeared.

Second, the subjective probability approach leads to misunderstandings when the person's belief is contrary to the objective probability. For example, a gambler rolling a single honest die after twelve rolls without getting a six, might have a strength of belief of .9 that a six will come up next, meaning under the subjective interpretation that the probability of getting a six is .9. But the probability of getting a six on the next roll of an honest die is not .9; it is $1 / 6$. Nor is the next roll probably going to be a six; it is probably not going to be a six, contra the gambler's fallacy. There is more to this discussion, but we do invite confusion when we say that the probability of getting a six with the honest die is .9

The prospects look dim for a useful deductively-valid interpretation of the raccoon and similar examples. 


\section{Conductive Reasoning}

All of the approaches I have so far considered attempt in some way fully to formalize qualified reasoning. If this full formalization were successful, there would be a reasonable hope, once we know that the reasons are acceptable or true, that deductive appraisal techniques could do the appraisal job by themselves, and the appraisal task could be turned over to a computer. I have tried to show that these formalizing attempts break down somewhere.

Carl Wellman (1971) and Trudy Govier (1999) in their depiction of what they call "conductive arguments" have expressed even stronger dissatisfaction with deductivism, and have attempted to provide legitimacy to some reasoning that does not satisfy deductive standards, but which they hold is good reasoning nevertheless. According to Govier (p. 166-67), "Wellman...claimed that there are no rules that could be given for the evaluation of conductive arguments," other than to think the argument through.

However, Govier thinks that we can do somewhat better than that, and I shall present her attempt to give some structure to such reasoning. It is a valiant effort, but for forthcoming reasons, I do not recommend her approach, though I do roughly endorse the spirit behind it, and shall comment on it.

For Govier, conductive arguments have "one or more premises...put forward as reasons supporting a conclusion [,] ... as relevant to that conclusion, as counting in favor of it, but not providing conclusive support for it" (p.155). Furthermore, for Govier, common characteristics of conductive reasoning include not being taken as entailments by the arguer or the audience (p. 155), the arguer's possibly acknowledging points that actually or apparently count against the conclusion ( $\mathrm{p}$. 155), and convergence. In interpretation of 'convergence,' she says, "That is to say, each premise constitutes, or is put forward as constituting, a distinct reason or piece of evidence that the arguer brings forward as relevant to his or her case. If some premises were to be removed, the relevance of the others to the conclusion would not be affected" (p. 156).

Govier offers nine very helpful questions (p. 170) to ask in appraising conductive arguments, questions that emphasize acceptability of, relevance of, and strength of support provided by the reasons; counterconsiderations; and total amount of support, on balance, provided for the conclusion. No mention is made of deductive standards, best-explanation standards, generalization standards, etc., although, as I shall argue, she uses deductive standards herself in elaborating the argument.

It seems odd that Govier should require that the relation not be taken as an entailment by the audience. How can the audience influence the nature of what is being offered?

I also wonder why she insists on convergence. Doing so eliminates a large number of arguments, including all that I have so far considered in this paper. Possibly she wants to avoid any hint of the use of deductive standards. But, as I 
shall show, her elaboration of the structure of an example of conductive argument that she offers seems inconsistent with her insistence on convergence. Here is the example:

She would be a good manager because she has considerable experience, she is very good at dealing with people, and she knows the business well (p. 158).

In this example, Govier apparently believes that each reason supports the conclusion independently of the others. Hence, for her, the manager argument satisfies the convergence condition. However, each could be an INUS condition (insufficient but necessary member of an unnecessary but sufficient set), ${ }^{6}$ all three together constituting the set, making these conditions dependent on each other. The argument itself does not tell us whether each reason is an INUS condition or an independent condition. So it is difficult to decide whether this is in fact a convergent argument at that point. But let us assume her interpretation.

She suggests ascribing assumptions that constitute a qualified universalizing of each reason because "reasons must have a degree of generality" (p. 171). For the manager argument, one such assumption is "Other things being equal, insofar as P1 is true, C" (p. 171), in which "P1" stands for "she has considerable experience," and " $C$ " stands for "She would be a good manager." The other two assumptions she offers for this example result from the successive substitution of 'P2' and 'P3' for 'P1.' 'P2' means "she is very good at dealing with people," and "P3" means "she knows the business well." That she calls the results "qualified universals" (p. 171) suggests strongly that the assumptions she ascribes are generalizations with a ceteris paribus qualification. This process of ascribing qualified universals is a much better idea than one she rejects, ascribing straight universals, such as, 'If $\mathrm{Pl}$ is true, then $\mathrm{C}$,' because, as she points out, the latter "are absurdly easy to falsify by counterexamples" (p. 171). I have similarly argued $^{7}$ (Ennis, 2001, p. 113).

However, she is assuming deductive standards in this qualified universalizing. Why not universalize as follows, 'Other things being equal, insofar as $\mathrm{C}$ is true, $\mathrm{Pl}$ ' (in which ' $\mathrm{Pl}$ ' and ' $\mathrm{C}$ ' are exchanged)? The problem with such a universalizing is that it fails to produce a deductively valid argument when the qualifier is omitted. The fallacy of affirming the consequent is committed. So her attempt to avoid the use of deductive standards is not successful. She uses the modus ponens or some other deductive standard, depending on how she develops the argument.

Another difficulty is the apparent assumption that the simplest qualified universals are the ones to ascribe to the parts of the argument. As I have argued elsewhere (Ennis, 1982, 2001), there is always a range of possible ways to complete an argument, varying primarily in their specificity.

Interestingly, when her qualified universals are added as assumptions, the argument becomes non-convergent. That is, the original $\mathrm{P} 1$ and its qualified universal depend on each other for providing support, another problem with the convergence requirement. 
Lastly, one wonders how Govier appraises the parts of the manager argument. Each part consists of a qualified universal, an instantiating fact, and the conclusion, making it a standard case of qualified reasoning because the conclusion would follow necessarily with the qualification removed. So in a way she ends up at the point at which this essay starts. More needs to be said.

In sum, Govier's conductive approach seems reasonable in spirit, but there are problems. The audience requirement seems inappropriate. The convergence requirement seems unduly narrow and difficult to apply, and she appears to violate it. Furthermore, although she apparently eschews the use of deductive standards in conduction, she needs them to show the relevance of the qualified universals. And lastly, her choosing the simplest qualified universal to complete the parts of her manager argument ignores the numerous other ways of completing the argument.

\section{A Situationally-Sensitive Approach to the Application of Qualified Soundness Standards}

How then should we apply soundness standards to qualified reasoning? I suggest an approach, using some formalism, but also calling for sufficient Sensitivity, Experience, Background Knnowledge, and Understanding of the Situation (Acronym: SEBKUS).

As I have argued (Ennis, 2001), classifying an argument as inductive, deductive, evaluative, etc., prior to evaluating it, although oft-recommended, is not a viable strategy. The alternative developed in that essay, which I assume here, is successively to apply legitimate sets of standards, judging the argument to be acceptable if one or more sets of standards are satisfied (manipulating the qualifications, if any, in the way I indicate below), and not acceptable if no set of standards is satisfied. ${ }^{8}$ The part of the approach I am about to suggest is only the application of loosened, or qualified, soundness standards to an argument.

Briefly, the general strategy in the loosening of soundness standards is to remove qualifiers (or somehow universalize, as in changing 'rarely' to 'never'), judge the qualifier-stripped argument-making use of a set of standards, reinsert the qualifiers, and judge again, in employing sufficient SEBKUS. In more detail,

1) Temporarily eliminate all the implicit and explicit qualifiers in an argument being prepared for the application of qualified soundness standards, including arguments leading to value judgments from implicit or explicit value principles. If a qualifier in a generalization is negative (like 'rarely'), create a negative universal.

2) While the eliminated qualifiers are missing, judge the reasoning (though not the reasons) using deductive standards. If invalid, stop (because deductive validity at this point in the process is a necessary condition 
for the satisfaction of qualified soundness standards) and go on to apply one or more other sets of standards. (Remember that the decision procedure is that if an argument satisfies no set of standards, it should be rejected, and if it satisfies some set of standards, such as qualified soundness standards, it should be accepted). If deductively valid, continue.

3) Reinsert the qualifiers to restore the original argument.

4) Judge the original reasons for their acceptability-or truth, employing SEBKUS.

5) Judge the total qualified argument carefully, taking into account the result of the judgments about the original reasons in Step 4; and employing sensitivity, experience, background knowledge, and understanding of the situation (SEBKUS).

These judgments, for which an argument appraiser should assume responsibility (just as we are expected to assume responsibility for any of our actions), are not wholly determined by the application of deductive standards, but do make explicit use of deductive standards, thus distinguishing this qualified soundness approach from that of conductive reasoning (although both emphasize attention to context, content, knowledge, and sensitivity), and from that of strict soundness (in the technical sense).

I shall exemplify these steps in application to the raccoon argument:

At the time of the reasoning and self-appraisal reported earlier (p.26), I had considerable experience with raccoons at that location (Sanibel, Florida) and other locations (including especially Oakwood, Illinois; Ithaca, New York; Champaign, Illinois; and Door County, Wisconsin). Raccoons had frequently walked across my yard while I was at the location of the offering of the argument and had continued at a healthy distance, walking, not running, in their own peculiar smooth way. Furthermore, I had once seen a raccoon that was in a metal trap/cage for removal to another place, and it was snapping, baring its teeth, and lunging. But in the open, of the hundreds of raccoons I have seen, none acted in a hostile manner, though all stayed at a distance of fifteen feet or more. I also had background knowledge to the effect that wild animals tend to shy away from humans, but when cornered, or trapped, or when their young are threatened, they can respond with violence; and when rabid, they do often attack. As I surveyed the situation (I looked carefully), nothing seemed different from my previous experience with raccoons in the open. There was no foaming, etc.

I believe that I was sensitive in appraising the situation. I was not upset or nervous. The time was about midday, and the weather was benign.

In explicitly applying the five steps when I reviewed my reasoning at the time, I removed the qualifier 'probably' and changed the 'rarely' to 'never' (Step 1), and judged the resulting argument to be deductively valid (Step 2). So the argument satisfied that necessary condition. I returned the argument to its original 
form (Step 3) and judged the two reasons to be acceptable (Step 4), employing, I believed, sensitivity, experience, background knowledge, and understanding of the situation (SEBKUS). I then made an overall appraisal of the argument, employing SEBKUS, and judged it to be a good argument, also judging the conclusion to be one for which I could legitimately provide the limited guarantee indicated by the word 'probably.' In looking back at the episode, I still believe that I satisfied the requirements of the five-step process, with sufficient SEBKUS, and was justified in drawing that conclusion.

The approach is, I believe, a reasonable way to loosen soundness standards when qualifiers are involved. I know of no better approach, but invite suggestions.

\section{Summary}

Qualified reasoning is reasoning containing implicit or explicit qualifying words like 'usually,' 'rarely,' 'probably,' 'probable,' 'likely,' 'almost certainly,' 'ceteris paribus,' and 'prima facie.' I have argued

1) That my original qualified-reasoning raccoon example is deductively invalid.

2) That comparable arguments like Toulmin's Petersen argument, Weddle's weather argument, and Plantinga's lifeguard argument are similarly deductively invalid, though their authors claimed otherwise.

3) That 'ceteris paribus' and 'etc.,' when used in the generalization only (assuming the simple forms considered in this essay) similarly make the argument deductively invalid. When the 'ceteris paribus' or 'etc.' also appears in the instantiating premise, if the coverage of the expression is deemed finite, deductive invalidity or uselessness holds sway, or the reasoning is not qualified reasoning; but, if the coverage is infinite, the truth or acceptability of the instantiating premise can not be ascertained, resulting in inability to justify the generating of the conclusion. All this is not to denigrate the employment of these two useful qualifiers.

4) That attempting to save the situation by adding a limited-to-the-evidence qualifier to the conclusion (as Plantinga did), if it does save the deductive validity (which I doubt), does so at the cost of offering the sort of conclusion that is usually of little interest.

5) That standard statistical syllogisms are similarly deductively invalid.

6) That interpreting the qualifiers as being equivalent to numbers cannot plausibly be done.

7) That interpreting 'probably' and 'likely' as degree-of-belief numbers obliterates real disagreements and leads to strange claims.

8) That a few forms of qualified reasoning appear to be deductively valid. 
9) That Govier's promotion of conduction is a move in the right direction, although the definition of 'conduction' is needlessly narrow, and the approach explicitly neglects, but implicitly employs, deductive standards.

The application of qualified soundness standards, which I use and suggest, calls for temporarily stripping the qualifications, judging the argument for its deductive validity (passing this test being necessary for continuation of the application of this set of standards), reinserting the qualifications, judging the truth or acceptability of the premises, employing sufficient sensitivity, experience, background knowledge, and understanding of the situation (SEBKUS), and, taking everything into account, make a final judgment of the argument with SEBKUS. All of this takes place in the context of the successive application of sets of standards in judging an argument, where satisfaction of no set of standards implies failure of the argument, and satisfaction of any set implies success of the argument.

Qualified reasoning is a hazardous area. I have set forth the proposed approach in considerable detail with occasional reminders because in the past I have found that it is easily misunderstood or misconstrued. If you have found the detail and reminders to be excessive, I apologize. In any case, I would welcome comments and suggestions.

\section{Notes}

'This essay is an elaboration of a portion of a more comprehensive essay, entitled "Argument Appraisal Strategy: A Comprehensive Approach" (Ennis, 2001), and is a significantly revised version of a paper presented at the May, 2001, meeting of the Ontario Society for the Study of Argumentation. I deeply appreciate the suggestions of John Canfield, Daryl Close, David Hitchcock, Shirley Pendlebury, and an anonymous reviewer.

${ }^{2}$ A position similar to ones taken by Skyrms (1975) and Hitchcock (1980).

${ }^{3}$ An anonymous reviewer who made many helpful suggestions urged me to attend to a distinction drawn by James Freeman $(1983,1991)$ between treating the "probably" as part of the conclusion (as I have done) and treating is as part of a logical operator (like the word "necessarily" as in, "It necessarily follows that..." Freeman urged the adoption of the second part of the distinction. Briefly, I did not choose to treat "probably" as part of an operator primarily because when we detach the conclusion and report or state it by itself, it would be misleading to omit the "probably."

${ }^{4}$ Personal communication, 2000.

${ }^{5}$ The Nichomachean Ethics, I, 3.

${ }^{6}$ To crib from J. L. Mackie (1993, p. 34).

${ }^{7}$ Assuming that she means this relationship to be between propositional functions rather than propositions.

${ }^{8}$ A less detailed version of this approach is in Ennis (1996, pp. 157-158). 


\section{References}

Aristotle. (1959). The Nichomachean Ethics of Aristotle. (Sir David Ross, Trans.). London: Oxford University Press.

Ennis, Robert H. (2001). "Argument Appraisal Strategy: A Comprehensive Approach," Infomal Logic, 21.2, pp. 97-140.

Ennis, Robert H. (1996). Critical Thinking. Upper Saddle River, NJ: Prentice Hall.

Ennis, Robert H. (1982). "Identifying Implicit Assumptions," Synthese, 51, pp. 61-86.

Ennis, Robert H. (1981). "A Conception of Deductive Logic Competence," Teaching Philosophy, 4, pp. 337-385.

Freeman, James B. (1983). "Logical Form, Probability Interpretations, and the Inductive/ Deductive Distinction," Informal Logic Newsletter, 5, pp. 2-10.

Freeman, James B. (1991). Dialectics and the Macrostructure of Arguments. New York: Foris Publications.

Govier, Trudy. (1999). The Philosophy of Argument. Newport News, VA: Vale Press.

Hitchcock, D. (1980). "Deductive and Inductive: Types of Validity, not Types of Arguments," Informal Logic Newsletter, 3(2), 7-15.

Mackie, J. L. (1993). "Causes and Conditions.” In E. Sosa and M. Tooley (Eds.), Causation. Oxford: Oxford University Press. pp. 33-55.

Plantinga, Alvin. (1993). Warrant and a Proper Function. New York: Oxford University Press.

Pollock, John L. (1995). Cognitive Carpentry: A Blueprint for How to Build a Person. Cambridge, MA: MIT Press.

Rescher, Nicholas. (1976). Plausible Reasoning. Amsterdam: Van Gorcum, Assen.

Scriven, Michael. (2003). "The Philosophy of Critical Thinking and Informal Logic." In Daniel Fasko, Jr. (Ed.), Critical Thinking and Reasoning. Cresskill, New Jersey: Hampton Press. pp. 21-45.

Skyrms, B. (1975). Choice and Chance: An Introduction to Inductive Logic (2nd ed.). Encino, CA: Dickenson.

Toulmin, Stephen. (1956). "Probability." In A. Flew (Ed.), Essays in Conceptual Analysis. New York: St. Martin's Press. pp. 157-191.

Toulmin, Stephen. (1964). The Uses of Argument. Cambridge: Cambridge University Press.

Urmson, J.O. (1956). "Parenthetical Verbs.” In A. Flew (Ed.), Essays in Conceptual Analysis. New York: St. Martin's Press. pp. 192-213.

Webster's Collegiate Dictionary. (5th ed.). (1947). Springfield, MA: G. \& C. Merriam Co. Weddle, Perry. (1979). "Inductive, Deductive." Informal Logic Newsletter, 2 (1), pp. 1-5. Wellman, Carl. (1971). Challenge and Response: Justification in Ethics. Carbondale, IL: Southern Illinois University Press.

Robert H. Ennis

University of Illinois $U-C$ 3904 Trentwood Place Sarasota FL, 34243

rhennis@uiuc.edu 